\title{
Person Occupation Date Range
}

National Cancer Institute

\section{Source}

National Cancer Institute. Person Occupation Date Range. NCI Thesaurus. Code C93989.

The date and time span specifying the start and end of a person's occupation. 